\title{
International Cooperation Combating Financial Proceeds of Crime
}

\section{Silvana Lule}

Prosecutor, Tirana District Prosecution, Albania

\section{Abstract}

The flow of illicit capital, into the financial circles of various states, is a serious threat to global security. To this end, an important part of the strategy to combat criminal proceeds is the coordination of work between states. Expanding investigative capacity across national borders is seen as an important factor in the success of the fight against crime. The exchange of information, between law enforcement agencies in different states, is one of the most effective policies for financial investigations aimed at tracking the proceeds of crime. This case, should be approciated in two aspects. On the one hand, it is necessary to adopt direct and at the same time joint interventions, to detect and monitor the movement of money or capital outside their borders. On the other hand, the conditions must be provided for an appropriate use of information and without hindering the movement of legal capital. The necessity of a common criminal policy, to deprive criminals of the proceeds of crime and the instruments for their commission, is clearly emphasized by international acts in this field. They encourage the widest possible cooperation between states for the purpose of investigating and prosecuting criminal assets.

Keywords: illicit income, proceed of crime, cooperation, convention, legal instruments, international organizations

\section{Introduction}

The biggest challenge in the fight against income from illegal activity is presented in international level. The fact that proceeds of crime are transferred between different states, in order to conceal their origin, is already known. In this regard, the differences between the domestic legislation of the states, in relation to the systems they use against illegal income, is used in their favour. In general, the latter move to countries where financial transparency is weaker. They are distributed in such a way, in order to make it difficult to track their flow, identification, location, ownership, etc. "Thus, prosecutions and seizures of proceeds of crime become more difficult, especially in 
cases involving foreign persons, banks and countries" (Poda ,2007). Consequently, the search for criminal property implies the jurisdiction of some states.

Factors, such as the globalization of the economy and the market, the fall of barriers to the movement of persons, capital, goods between states, etc., have favored the development of criminal phenomena, such as organized crime. The new technological system, regarding the means of payment, has been used by them in money laundering. In this way, large sums of money are transferred to other countries electronically. Illegal capital moves to several financial institutions of different states, before being legally invested. Also, from a structural point of view, money laundering, in its second phase, may involve several states. Specifically, it is about transporting funds from one country to another, so that they are returned to the country of origin under the guise of legal income (Poda,2007).

It is a well-known fact that various money laundering practices affect the economic and financial market, thus reinforcing the presence of organized crime. Moreover, the concern that arises, due to the link between various traffickers and terrorist organizations, is current. This connection leads to joint activities, to the transfer of funds between them for the respective purposes. The means by which terrorists transfer funds around the world, including why not non-profit organizations, are the ones that should be in the spotlight of the authorities. "The more the investigation goes into these activities, the more international connections come to light, of any level, the interests of certain groups, compromises of different environments" (Poda,2007).

The flow of illicit capital, into the financial circles of various states, is a serious threat to global security. To this end, an important part of the strategy to combat criminal proceeds is the coordination of work between states. Expanding investigative capacity across national borders is seen as an important factor in the success of the fight against crime. The exchange of information, between law enforcement agencies in different states, is identified as one of the most effective policies for financial investigations aimed at tracking the proceeds of crime. In this case, care must be taken in two aspects. On the one hand, it is necessary to adopt direct and at the same time joint interventions, to detect and monitor the movement of money or capital outside their borders. On the other hand, the conditions must be provided for an appropriate use of information and without hindering the movement of legal capital.

International co-operation should enable investigative assistance in identifying and tracking property, securing documents for the implementation of provisional measures and confiscation, based on the factual requests of a foreign state, with the same priority as in internal procedures" (Expanatory Report, Convention on Laundering, Search, Seizure and Confiscation of the Proceeds of Crime, Council of Europe, http://convention.coe.int.) 
The necessity of a common criminal policy, to deprive criminals of the proceeds of crime and the instruments for their commission, is clearly emphasized by international acts in this field. They encourage the widest possible cooperation between states for the purpose of investigating and prosecuting the confiscation of criminal assets (Article 15/1 of the Convention "On the Laundering, Search, Seizure and Confiscation of the Proceeds from Crime and on the Financing of Terrorism).

\section{International Cooperation instruments}

Due to the dangers that such phenomena imply, when it is extended beyond the borders of a state, there have been significant initiatives at the international level. They emphasize the necessity of cooperation in three main directions:

- in providing information,

- in freezing accounts, seizing and confiscating assets,

- in handing over criminals to the respective states.

Before addressing specific aspects of cooperation, it is necessary to define the normative framework, which regulates jurisdictional relations with foreign authorities in this field. "These relations are regulated by international agreements, accepted by the Albanian state, by the general accepted principles and norms of international law, as well as the provisions of Title X of the Code of Criminal Procedure." In the absence of agreements regulating these relations, they will be regulated by criminal procedural provisions.

Turning to the initiatives of the international community in the search for criminal property, it is worth mentioning the fact that they have had an important role for significant changes in domestic legislation. In addition to conventions such as "On extradition", "On mutual legal assistance in the criminal field", "On the transfer of proceedings in criminal matters", the framework of recent international agreements has been focused on the field of prosecution of illegal assets.

The first convention to provide for the confiscation of the proceeds of crime and the incrimination of money laundering was the United Nations Convention against Illicit Traffic in Narcotic Drugs and Psychotropic Substances. It was adopted in Vienna in 1988 and is otherwise known as the Vienna Convention.

The United Nations Convention against Corruption and the Convention against Transnational Organized Crime and its two additional protocols, also go in the same direction. The last two protocols of the Convention refer to the fight against migrant trafficking by land, air and sea and the prevention and punishment of trafficking persons, especially women and children.

As it can be seen, a characteristic of the first international acts is that they extend cooperation in the confiscation of the proceeds of certain criminal offenses. However, the situation changed quickly. In 1990 the international money laundering struggle was supplemented by the Strasbourg Agreement "On Laundering, Screening, 
Capturing and Confiscating the Proceeds of Crime". Within the main purpose of its adoption, which is the fight against money laundering, it also emphasizes cooperation in the search, seizure and confiscation of proceeds of crime. "This convention marks a fundamental development in the fight against money laundering, fixing a series of rules that highlight the need to prosecute the proceeds of crime and facilitate judicial and administrative cooperation between states" (Pollari, Cioppo, 2006)

It allows to be attacked with temporary measures, the benefits deriving from any kind of crime, regardless of whether or not the state has criminal jurisdiction over the underlying crime. The fight against money laundering, at the international level, finds significant support and evolution, above all in the Council of Europe Convention on Laundering, Search, Seizure and Confiscation of the Proceeds from Crime and on the Financing of Terrorism. Internationally, it is known as the Warsaw Convention. This marks one of the latest developments in the fight against money laundering. The Convention comes as a completion of the above mentioned agreement. It has added some predictions in light of the new demands nowadays, induced by international criminal developments in relation to terrorism.

These two Conventions are important because they have a wider range in the fight against proceeds of crime. In any case, they are seen as related and cannot be interpreted in contradiction with other international instruments, dealing with the same issues. For example, none of their provisions can be interpreted as restricting the rights provided in the European Convention on Human Rights and its protocols. The following are some of the key aspects of the obligations they impose.

\subsection{Characteristics of international instruments}

International acts, in the pursuit of illicit wealth, are focused on two main directions.

First, they require the criminalization of actions aimed at concealing the origin of money from illegal activity, e.g. narcotics trafficking, corruption, organized crime, etc.

Second, they appreciate the importance of mutual legal assistance in investigating and confiscating the proceeds of crime.

In the context of money laundering, the agreements also require the criminalization of providing assistance, to any person involved in such crimes, in order to escape criminal liability for his or her conduct. At the same time, they consider the importance of the liability of the legal person. This liability does not necessarily have to be criminal. It is enough for the measures to be effective and proportionate. The pursuit of criminal proceeds does not take into account the fact whether or not the main criminal offense is within the jurisdiction of the party. They also stipulate the obligation that, such crimes should be included in the domestic law of States, in those crimes for which extradition is permitted.

The conventions emphasize the obligation of mutual legal assistance in investigation, in order to gather evidence. The request can be addressed to a party to obtain 
evidence, legal acts, without invoking the principle of banking secrecy or claiming the fiscal character of the criminal offense. It is especially important to obtain banking, financial or commercial files or to use special investigative techniques, e.g. seizure of telecommunications, access to information systems, surveillance of bank accounts, etc. These investigative steps are taken in order to identify assets subject to confiscation, as well as to take provisional measures on them, such as. freezing / blocking and sequestration.

Almost every one of them, encourages states to apply reversal of the burden of proof. This means that states, in accordance with their domestic law, should consider the possibility of requiring the subjects to demonstrate the origin of the presumed illicit products or of the property, subject to confiscation. This provision can not be interpreted as an obligation to return the burden of proof, in a criminal process in finding the guilty person.

It is understood that cooperation in the field of search and confiscation of the proceeds of crime, requires the adaption of the legal framework of states between them. This does not mean the unification of the legislations of different states, but the fact that the necessary legislative and operational measures must be taken in order to respond to the requests of other parties.

\section{International organizations operating in this field}

The complexity of the phenomenon of money laundering and the consequent necessity of adopting a strategy at the national level, has imposed the creation of various organizations, in addition to the ratification of conventions in this field. Also, projects have been designed to assist in various areas to fight crime proceeds. Such have been PACO funded by the Council of Europe, CARPO, etc. In this part, will be mentioned those organizations, whose recommendations Albania follows.

FATF was established in 1989. It is an organization that assists states in carrying out legislative reforms,in the area of money laundering

(http://www.oecd.org/document/9/0,3343,en_32250379). Its purpose is to study the relationship between crime and finance and propose solutions. It works on the basis of recommendations and sets standards internationally. Its task is to observe the phenomenon and verify whether the measures taken or proposed, are current Its recommendations can be divided into four groups (Methology for Assesing Compliance with the FATF 40 Recomandations and with the FATF 9 Special Recomandations. http://www.fatf-gafi/document/9/0,399078):

1) general inclusion of the matter, inclusion of the criminal offense of money laundering in the domestic legal system,

2) legislative initiatives to combat this criminal phenomenon,

3) institutional measures to stop the pollution of the financial system from money laundering and terrorist financing, 
4) strengthening international cooperation in this field.

Along with anti-money laundering measures, the global fight against terrorism and its financing, is a priority policy, for many countries. FATF focused on new threats from terrorist financing in the international system, issued specific recommendations, as the international standard on the fight against terrorist financing. It should be remembered that the FATF has compiled a "black list" of countries that do not cooperate in these areas. This list has regressed over time.

From the control of the effectiveness of the recommendations it has been verified that, almost every state has included the figure of money laundering crime. FATF has also highlighted the importance of each state building a financial intelligence center, to adopt a system for analyzing suspicious operations and recording them, over a certain amount. It has developed the methodology for the joint evaluation process, which is also used by MONEYVAL. It is especially worth noting, for the purpose of this topic, recommendation no. 3. It provides measures to confiscate the proceeds of crime and encourages countries to consider them, without requiring a criminal conviction or requiring subjects/persons to demonstrate the legal origin of the property subject to confiscation.

MONEYAL is the Select Committee of Experts of the Council of Europe (http://www.oecd.org/document/46/0,3343,en_32250379). It was set up in 1997 and operates in the field of money laundering. It assesses the compliance of the measures taken by its members, with the relevant international standards against money laundering and terrorist financing, taking into account the recommendations of the FATF. In cooperation World Bank, it has developed a common method of combating money laundering and terrorist financing. MONEYAL drafts relevant reports regarding the measures taken by the states and at the same time, makes recommendations regarding the problems it identifies.

Among the priorities of the Council of Europe is the fight against corruption. The need to promote co-operation between states against it, including links to organized crime and money laundering, has prompted Council of Europe member states to set up a separate organization in this area. GRECO was established in 1999 and is a committee of this Council, which aims to help states fight corruption, by monitoring the measures they have taken to meet the commitments made in this area (http://www.greco.coe.in). GRECO has also adopted twenty principles, guiding the fight against corruption. In this way, it helps to identify the flaws and shortcomings of national mechanisms against it, as well as to promote the necessary legislative, institutional and practical reforms. Its conclusions and recommendations are a good source of information on the shortcomings of confiscation measures in relation to this criminal offense. 


\section{Cooperation between Financial Information Units}

The processing of financial data and their outcome are an important part of the process of searching for illegal assets. This fact has attracted the attention of states, to create specialized services in data collection and analysis, in relation to financial transactions, especially suspicious ones, for a more effective activity in the prevention and repression of money laundering. International conventions in this field impose the obligation of the ratifying states to establish this special institution, known as the Financial Information Unit.

This institution has competencies in two main directions, money laundering investigation and terrorist financing. Although, the provision is written in binding terms, the methodology of accessing data is left to the discretion of the states. There has been a debate at the international level, regarding the attribution of different competencies to the units. The debate at the international level was important (Pollari, Cioppo, 2006):

-to determine the characteristics of these bodies, as bodies with outstanding financial competencies,

-to promote their central role in terms of collecting and analysing relevant bank data and in the exchange of information with foreign correspondent bodies,

-to avoid the concentration of competencies and above all, the interference with other bodies of the fight against this phenomenon.

The international character that money laundering and terrorist financing is taking over time, requires effective cooperation and coordination between states. Thus, the necessity of exchanging information is evident, not only between law enforcement agencies at the national level, but also with other counterparts abroad. Cooperation between units of different countries, at the same institutional level, contributes to the success of the global fight against money laundering and terrorist financing. It also increases their individual effectiveness.

The Council of Europe member states, which have ratified the Warsaw Convention, have established EGMONT GROUP (Statement of Purpose of the Egmond Group of Financial Intelligence Units, Guernsey, 23 june 2004. http://www.egmondgroup.coe.int.)

It is an intergovernmental body, that monitors the function and cooperation of the financial intelligence units, of the States. Its purpose is to improve the respective national programs, which use such units to combat money laundering and terrorist financing. The rules of cooperation between these institutions are provided in Article 46 of the Convention "On the laundering, search, seizure and confiscation of the proceeds of crime and on the financing of terrorism".

Financial Information Units exchange, spontaneously or on request, any information that may be relevant in the fight against money laundering, to the investigation of 
financial transactions. If the request is made in accordance with the provisions of the Convention, the F.I.U. provides all possible financial information and data required for legal execution, according to its content. It does this even without the need for a formal letter.

This way, at the request of a foreign counterpart, the F.I.U. suspends or refuses to give consent to a transaction, subject to the same conditions as its domestic law, relates to the postponed transactions. Such an action will be taken when it is given that the transaction involves money laundering and it would have been suspended or consent would not have been given, if the transaction were the subject of an internal report, as a suspicious transaction. If required by domestic law, the postponement or suspension will be by court order.

It is important to highlight here that this cooperation is different, compared to other relations of international cooperation. First, this cooperation is not realized through a central authority, which for the effect of albanian law is the Ministry of Justice. This is seen this way, in order the institutional cooperation between the states in this regard to be as fast and efficient as possible. Second, the rejection of a request for cooperation between these institutions is not based on the cases provided in Article 28 of the Convention. They belong exclusively to other forms of co-operation between states.

The law "On the prevention of money laundering" defines the main directions of cooperation of this institutions, in international level. The responsible authority coordinates with counterpart bodies and international institutions, in terms of reporting to the prosecutor's office, for facts and evidence related to the criminal offense of "money laundering", finding and identifying the source of income and proceeds of crime. In the framework of international cooperation, the responsible authority informs the specialized financial units and other designated authorities abroad, regarding the data and documents that it possesses. It cooperates with counterpart units and institutions, in order to exchange data on identification, discovery of sources, blocking and temporary freezing of various transactions, sequestration of proceeds of crime. It also has the right to request information and documents from the latter, in order to detect and investigate illegal money laundering activities. The responsible authority and international organizations or institutions provide each other with maximum mutual assistance, in the exchange of legal documents, for persons who have been subject to legal measures and confiscation.

\section{Conclusions and Recommendations}

Cooperation between states is very important in the search for criminal property. A significant part of the proceeds of crime are transferred to other countries, in order to conceal their origin. The most important form of cooperation in criminal property search, is mutual legal assistance. It is seen especially in terms of providing evidence, but also taking provisional measures such as freezing or sequestration. The 
conventions also provide for the obligation to cooperate in the confiscation of proceeds of crime. In this regard, importance is given to the return of criminal assets to the requesting state. In order to guarantee the rule of law, as well as the public safety, greater importance must be given to cooperation between states in the pursuit of illegal income. Although conventions in this area have evolved and tried to capture many aspects of it, other bilateral/multilateral agreements between states can be processed, agreements that provide for direct ways of cooperation between law enforcement agencies. This is because the procedure followed through the letterrogatory, which is initially given way by the relevant ministry, brings its delays. The latter would bring faster results and eliminate the possibility of transferring or concealing illicit proceeds.

\section{References}

[1] Nicolo Pollari, Alberto del Cioppo, Patrimonial investigation technique for the fight against organized crime, fifth edition, LAURUS ROBUFFO

[2] Zamir Poda,Transnational Organized Crime, Morava Publications

[3] H. Islami, A. Hoxha, I.Panda,"Criminal Procedure”, Tiranë 2003

[4] Convention on "Laundering, Search, Seizure and Confiscation of the Proceeds of Crime", Council of Europe, ETS no.141

[5] Convention "On the Laundering, Search, Seizure and Confiscation of the Proceeds from Crime and on the Financing of Terrorism", Council of Europe, CETS no. 198 